\title{
Evasion of Apoptosis as a Cellular Stress Response in Cancer
}

\author{
Simone Fulda \\ Ulm University, Children's Hospital, Eythstraße 24, 89075 Ulm, Germany \\ Correspondence should be addressed to Simone Fulda, simone.fulda@uniklinik-ulm.de
}

Received 27 July 2009; Accepted 6 November 2009

Academic Editor: Adrienne M. Gorman

Copyright ( $) 2010$ Simone Fulda. This is an open access article distributed under the Creative Commons Attribution License, which permits unrestricted use, distribution, and reproduction in any medium, provided the original work is properly cited.

One of the hallmarks of human cancers is the intrinsic or acquired resistance to apoptosis. Evasion of apoptosis can be part of a cellular stress response to ensure the cell's survival upon exposure to stressful stimuli. Apoptosis resistance may contribute to carcinogenesis, tumor progression, and also treatment resistance, since most current anticancer therapies including chemotherapy as well as radio- and immunotherapies primarily act by activating cell death pathways including apoptosis in cancer cells. Hence, a better understanding of the molecular mechanisms regarding how cellular stress stimuli trigger antiapoptotic mechanisms and how this contributes to tumor resistance to apoptotic cell death is expected to provide the basis for a rational approach to overcome apoptosis resistance mechanisms in cancers.

\section{Introduction}

Tissue homeostasis is characterized by the balance between proliferation and cell growth on one side and cell death on the other side [1]. In response to stressful stimuli, cells usually mount a cellular stress response to ensure survival [2]. Under physiological conditions, such a stress response limits tissue damage. However, in cancer cells activation of pathways that favor cell survival instead of cell death under stressful conditions may contribute to tumorigenesis. In addition, this adaptive stress response promotes the development of acquired resistance, since current treatment approaches such as chemotherapy and irradiation trigger cellular stress pathways, and thus, initiate the activation of survival cascades and anti-apoptotic mechanisms [3]. Apoptosis or programmed cell death is the cell's intrinsic death program that regulates various physiological as well as pathological processes and that is evolutionary highly conserved [1]. Hence, further insights into the molecular mechanisms of how cellular stress signals trigger antiapoptotic mechanisms and how this contributes to tumor resistance to apoptotic cell death are expected to provide the basis for a rational approach for the development of new molecular targeted therapies.

\section{Signaling to Apoptotic Cell Death and Cellular Stress}

There are two major apoptosis signaling pathways, that is, the death receptor (extrinsic) pathway and the mitochondrial (intrinsic) pathway [4]. Under most circumstances, activation of either pathway eventually leads to proteolytic cleavage and thus activation of caspases, a family of cysteine proteases that act as common death effector molecules [5]. Accordingly, caspases are responsible for many of the biochemical and morphological hallmarks of apoptotic cell death by cleaving a range of substrates in the cytoplasm or nucleus [5]. Ligation of death receptors of the tumor necrosis factor (TNF) receptor superfamily such as CD95 (APO-1/Fas) or TRAIL receptors by their corresponding natural ligands, that is, CD95 ligand or TRAIL, results in the recruitment of caspase- 8 into a multimeric complex at the plasma membrane, the death-inducing signaling complex (DISC) $[6,7]$. This in turn leads to caspase- 8 activation, which can then directly cleave downstream effector caspases such as caspase-3 [7]. Alternatively, caspase- 8 can promote outer mitochondrial membrane permeabilization by cleaving Bid, a $\mathrm{BH} 3$-only protein that translocates to mitochondria upon cleavage and causes cytochrome $\mathrm{c}$ release [8]. The mitochondrial pathway is initiated by the release 
of apoptogenic factors such as cytochrome c, apoptosisinducing factor (AIF) second mitochondria-derived activator of caspase (Smac)/direct IAP Binding protein with Low pI (DIABLO) or Omi/high temperature requirement protein A (HtrA2) from the mitochondrial intermembrane space into the cytosol [9]. The release of cytochrome c into the cytosol triggers activation of caspase-3 via the formation of a large cytosolic complex, which is called the apoptosome and consists of cytochrome c, Apaf-1, and caspase-9 [9]. Smac/DIABLO or Omi/HtrA2 promotes caspase activation by binding to Inhibitor of Apoptosis (IAP) proteins and thereby disrupts the interaction of IAPs with caspase- 3 or $-9[9,10]$. Accidental stimulation of the apoptotic machinery can have detrimental effects on cell survival. Therefore, cancer cells react to cellular stress signals by mounting an anti-apoptotic response, which enables cancer cells to evade apoptotic cell death and ensures cell survival [11]. A wide range of stress signals has been identified, which may evoke a cell survival program in case of sublethal damage, while cell death is usually initiated if the damage is too severe, that is, starvation, hypoxia, DNA damaging drugs, irradiation, ER stress, and reactive oxygen species just to name a few [2].

The molecular mechanisms that initiate cell death upon cellular stress stimuli have often not exactly been identified and likely depend on the individual stimulus. For example, following exposure to genotoxic substances, damage to DNA or to other critical molecules is considered to be a common initial event which is then transmitted by the cellular stress response to the activation of cellular effector systems such as the apoptotic machinery [12]. Various stressinducible molecules, for example, JNK, MAPK/ERK, NF$\kappa \mathrm{B}$, or ceramide have been implicated in propagating the apoptotic signal [13-15].

Besides caspase-dependent and caspase-independent apoptosis, additional non-apoptotic modes of cell death also exist and have gained increasing attention over the last years, including necrosis, autophagy, mitotic catastrophe, and lysosomal cell death $[16,17]$. While resistance to these cell death modalities can also contribute to evasion of cell death under stress conditions, the discussion of these alternative modes of cell death is beyond the scope of this review.

\section{Evasion of Apoptosis in Response to Cellular Stress in Cancers}

A characteristic feature of human cancers is the evasion of apoptosis in response to stress stimuli, which contributes to both tumorigenesis and treatment resistance [18]. In principle, cell death pathways can be blocked at different levels of the signaling cascade by upregulation of antiapoptotic proteins and/or by downregulation or dysfunction of proapoptotic molecules. Examples of altered apoptosis signaling pathways that contribute to stress resistance in human cancers will be discussed in the following paragraphs (Figure 1).
3.1. Evasion of the Death Receptor Pathway. Death receptors are part of the tumor necrosis factor (TNF) receptor gene superfamily, which comprises more than 20 proteins, for example, CD95 (APO - 1/Fas), TRAIL receptors, and TNF receptor 1 (TNFRI) $[7,19]$. Death receptors exert many different biological functions, including the regulation of cell death and survival, differentiation, and immune regulation $[7,19]$. Members of the TNF receptor family share a characteristic cytoplasmic domain called the "death domain," which is pivotal for transducing the death signal from the cell's surface to intracellular signaling pathways $[7,19]$.

Signaling via death receptor can be impaired in human cancers via downregulation of receptor surface expression as part of an adaptive stress response. For example, in chemotherapy-resistant leukemia or neuroblastoma cells, downregulation of CD95 expression was identified as a mechanism of acquired drug resistance $[20,21]$. For the apoptosis-inducing TRAIL receptors TRAIL-R1 and TRAIL$\mathrm{R} 2$, abnormal transport from intracellular stores such as the endoplasmatic reticulum to the cell surface rendered colon carcinoma cells resistant to TRAIL-induced cell death [22]. Further, membrane expression of death receptors can be reduced by epigenetic changes such as $\mathrm{CpG}$-island hypermethylation of gene promoters in response to stress signals $[23,24]$.

Abnormal expression of decoy receptors presents an alternative mechanism of resistance to TRAIL- or CD95induced apoptosis. To this end, the decoy receptor 3 (DcR3), which counteracts CD95-mediated apoptosis by competitively binding CD95 ligand, was shown to be overexpressed in lung carcinoma or colon carcinoma and in glioblastoma $[25,26]$ and TRAIL-R3; a decoy receptor for TRAIL was reported to be expressed at high levels in gastric carcinoma [27].

In addition, anti-apoptotic proteins with a death effector domain (DED) such as cellular FLICE-Inhibitory Protein (cFLIP) and phosphoprotein enriched in diabetes/ phosphoprotein enriched in astrocytes-15 $\mathrm{kDa}(\mathrm{PED} / \mathrm{PEA}-15) \mathrm{can}$ be aberrantly expressed upon cellular stress $[28,29]$. For example, high oxygen tension (hyperoxia) has been reported to lead to upregulation of cFLIP, which inhibited apoptosis during hyperoxia by suppressing both extrinsic and intrinsic apoptotic pathways, the latter via inhibition of Bax [30]. Because of their sequence homology to caspase- 8 , both cFLIP and PED can be recruited into the death-inducing signaling complex (DISC) upon receptor ligation instead of procaspase- 8 , thereby preventing caspase- 8 activation $[28$, 29].

Moreover, the expression of caspase- 8 or its function is impaired by genetic or epigenetic mechanisms in various cancers. For example, caspase- 8 mutations were identified in some tumors, that is, in colorectal and head and neck carcinomas, although the overall frequency is low $[31,32]$. In addition, homo- or heterozygous genomic deletions were detected in neuroblastoma [33]. Alternative splicing of intron 8 of the caspase- 8 gene resulting in the generation of caspase-8L, a catalytically inactive splice variant presents another mechanism of caspase-8 inactivation $[34,35]$. Epigenetic silencing secondary to hypermethylation of regulatory 


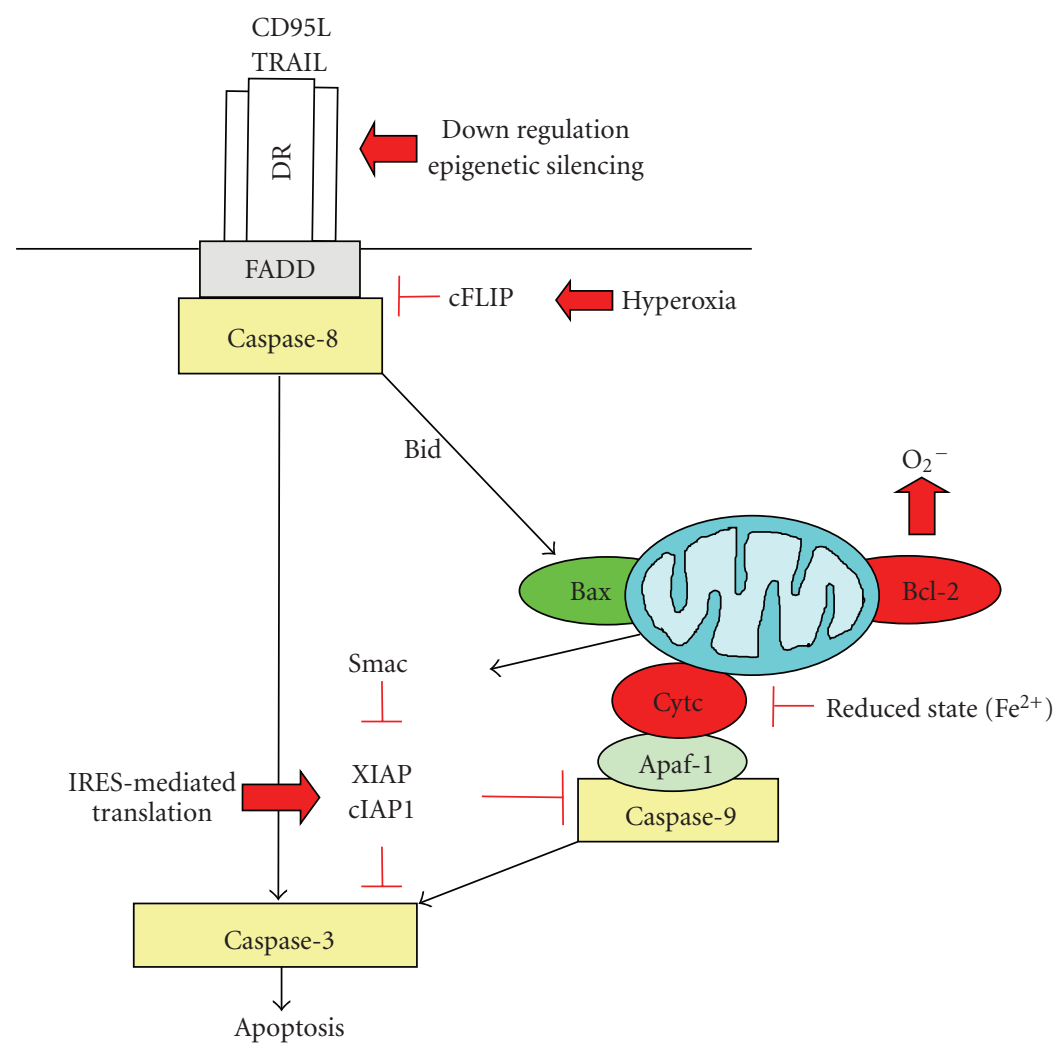

FIGURE 1: Interplay of cellular stress signals with apoptosis pathways. Signaling via the death receptor pathway can be inhibited by downregulation or epigenetic silencing of death receptors (DRs) or upregulation of cFLIP by hyperoxia. In the mitochondrial pathway, Bcl-2 favors a prooxidant milieu that promotes survival, while the reduced form of cytochrome $\mathrm{c}$ is inhibited in its activity to trigger caspase activation via the apoptosome. At the postmitochondrial level, translation of XIAP and cIAP1 is sustained via an IRES-dependent mechanism even under cellular stress conditions. See text for more details.

sequences of the caspase- 8 gene occurs in various tumors, for example, neuroblastoma, malignant brain tumors, Ewing tumor, retinoblastoma, rhabdomyosarcoma, or small lung cell carcinoma [33, 36-39]. Furthermore, phosphorylation of caspase- 8 on tyrosine 308 by, for example, Src has been shown to interfere with its proapoptotic activity [40].

\subsection{Evasion of the Mitochondrial Pathway}

3.2.1. Bcl-2 Family Proteins. The Bcl-2 family of proteins consists of both anti-apoptotic proteins, for example, Bcl-2, $\mathrm{Bcl}-X_{L}$, and $\mathrm{Mcl}-1$, as well as proapoptotic molecules such as Bax, Bak, and BH3 domain only molecules [8]. There are currently two models to explain the activation of Bax and Bak by BH3-only proteins. The direct activation model holds that $\mathrm{BH} 3$-only proteins, which act as direct activators such as Bim and the cleaved form of Bid (tBid), bind directly to Bax and Bak to trigger their activation, while $\mathrm{BH} 3$-only proteins that act as sensitizers, for example, Bad, bind to the prosurvival $\mathrm{Bcl}-2$ proteins [41]. According to the indirect activation model, $\mathrm{BH} 3$-only proteins activate Bax and Bak in an indirect fashion by engaging the multiple anti-apoptotic $\mathrm{Bcl}-2$ proteins that inhibit $\mathrm{Bax}$ and $\mathrm{Bak}$, thereby releasing their inhibition on Bax and Bak $[42,43]$. Regardless of the exact mode of Bax and Bak activation, the ratio of antiapoptotic versus proapoptotic $\mathrm{Bcl}-2$ proteins rather than the expression levels of one particular molecule of the Bcl-2 family regulates apoptosis sensitivity.

An increase in the ratio of anti- to proapoptotic Bcl-2 proteins has been detected in various cancers and has been correlated to tumor cell survival and apoptosis resistance. More recently, $\mathrm{Bcl}-2$ has also been implicated in the regulation of the intracellular redox status [44]. Bcl-2 localizes to mitochondrial membranes as well as the endoplasmatic reticulum and the nuclear envelope, which are all sites of ROS production [45]. While $\mathrm{Bcl}-2$ has initially been described as an anti-oxidant because of its inhibitory effect on $\mathrm{H}_{2} \mathrm{O}_{2}$-induced lipid peroxidation [46], there is also evidence that $\mathrm{Bcl}-2$ may promote a prooxidant intracellular milieu. Accordingly, ectopic expression of $\mathrm{Bcl}-2$ resulted in an elevated constitutive level of superoxide anion and intracellular pH in leukemia cells [47]. Conversely, reduction of intracellular superoxide sensitized Bcl-2-overexpressing tumor cells to apoptotic stimuli independent of the mitochondria [47]. These findings provide a link between oncogene-mediated alterations in the intracellular redox status and cell survival. 
3.2.2. Cytochrome c. Besides Bcl-2, also cytochrome $\mathrm{c}$ has been implicated in the redox regulation of apoptosis. Once cytochrome $\mathrm{c}$ is released from mitochondria into the cytosol, it triggers formation of the cytochrome c/Apaf-1/Caspase9-containing apoptosome, which in turn lead to activation of caspase-9 and downstream effector caspases [48]. There is recent evidence that also the redox state of cytochrome $\mathrm{c}$ is involved in the regulation of apoptosis. To this end, the oxidized form of cytochrome $\mathrm{c}(\mathrm{Fe}(3+))$ has been reported to induce caspase activation via the apoptosome, while the reduced form of cytochrome $\mathrm{c}(\mathrm{Fe}(2+))$ is unable to do so [49-51]. Several mechanisms have been discussed to be responsible for this redox-mediated regulation of cytochrome c activity, including different affinities of the oxidized versus the reduced form of cytochrome $\mathrm{c}$ for binding to Apaf-1, different abilities of these cytochrome $\mathrm{c}$ forms to activate Apaf-1, or, alternatively, different affinities for other factors not belonging to the apoptosome. Regardless of the exact mechanisms, this regulation of the redox state of cytochrome $\mathrm{c}$ opens the possibility of controlling the effector phase of apoptosis at a postmitochondrial level.

Besides these genetic alterations in Bcl-2 family proteins, impairment of mitochondrial apoptosis may also occur at the postmitochondrial level. For example, expression level or activity of Apaf-1 may be reduced due to promoter hypermethylation or loss of heterozygosity at chromosome 12q22-23, which in turn leads to impaired assembly of a functional apoptosome [52-56].

\subsection{Evasion of Apoptosis via Aberrant Expression of "Inhibitor} of Apoptosis" (IAP) Proteins. Moreover, tumor resistance to apoptosis may be caused by aberrant expression or function of "Inhibitor of Apoptosis" (IAP) proteins. IAP proteins are a family of endogenous caspase inhibitors with eight human members, that is, XIAP, cIAP1, cIAP2, survivin, livin (ML-IAP), NAIP, Bruce (apollon), and ILP-2 [10, 57]. All IAP proteins have at least one baculovirus IAP repeat (BIR) domain that is required for classification as IAP family protein. This domain is also the region of the protein that mediates the interaction with caspases [58]. Among the IAP family proteins, XIAP exhibits the strongest antiapoptotic properties and inhibits apoptosis signaling by binding to active caspase- 3 and -7 and by preventing caspase9 activation [59].

The expression and function of IAP proteins are tightly regulated by several mechanisms, among them is translational regulation [60]. To this end, it is particularly interesting to note that XIAP and cIAP1 belong to the proteins, which are translated via an internal ribosome entry site (IRES). This unique property enables protein translation of these IAP proteins even under cellular stress conditions when protein synthesis is usually shut down, for example, because of caspase-dependent breakdown of eukaryotic translation initiation factors coupled with activation of the doublestranded RNA-activated protein kinase PKR [61].

Typically, mRNA molecules are translated via a capdependent translation mechanism [62]. However, the mRNAs encoding XIAP or cIAP1 protein contain very long
5' untranslated regions (UTRs), which are not amenable to a ribosome-scanning translation initiation mechanism and thus, require a cap-independent translation initiation mechanism, that is, IRES-mediated translation [60]. IRESmediated translation allows for the continued translation of XIAP and cIAP1 even under conditions where capdependent translation is inhibited such as cellular stress [60]. In addition, IRES-mediated translational regulation of XIAP and cIAP1 expression enables a rapid response to transient cellular stress conditions in order to delay cell death and ensure survival. Of note, cellular stress signals, including low-dose irradiation, anoxia, serum starvation and chemotherapeutic drugs, have been reported to stimulate the IRES activity of XIAP or cIAP1 [63-66]. This is in line with the concept that such stress signals promote cell survival under stress conditions, at least in part, via IRES-mediated upregulation of anti-apoptotic proteins.

\section{Conclusions}

Evasion of apoptosis is one of the hallmarks of human cancers that promote tumor formation and progression as well as treatment resistance. Cellular stress signals can contribute to evasion of apoptosis by activating anti-apoptotic and cell survival programs that ultimately block cell death. This interference with proper apoptosis signaling under stress conditions can occur at different points of the apoptosis signaling network, for example, within the death receptor or the mitochondrial pathway or at the postmitochondrial level. Whether or not cellular stress eventually engages cell survival or cell death programs also depends on the type and strength of the stress stimulus as well as the cell type. A better understanding of the molecular mechanisms of this interplay between the cellular stress response and antiapoptotic programs is expected to yield novel molecular targets for therapeutic interventions. The aim is to prevent protective responses in order to maximize the antitumor activity of anticancer treatment approaches. This strategy will hopefully lead to more effective treatment options for cancer patients.

\section{Acknowledgments}

Work in the author's laboratory is supported by grants from the Deutsche Forschungsgemeinschaft, the Deutsche Krebshilfe, the Bundesministerium für Bildung und Forschung, Wilhelm-Sander-Stiftung, Else-Kröner-Fresenius Stiftung, the Novartis Stiftung für Therapeutische Forschung, the European Community (ApopTrain, APO-SYS), and IAP6/18.

\section{References}

[1] R. A. Lockshin and Z. Zakeri, "Cell death in health and disease," Journal of Cellular and Molecular Medicine, vol. 11, no. 6, pp. 1214-1224, 2007.

[2] D. Kültz, "Molecular and evolutionary basis of the cellular stress response," Annual Review of Physiology, vol. 67, pp. 225257, 2005. 
[3] S. Fulda and K.-M. Debatin, "Extrinsic versus intrinsic apoptosis pathways in anticancer chemotherapy," Oncogene, vol. 25, no. 34, pp. 4798-4811, 2006.

[4] M. O. Hengartner, "The biochemistry of apoptosis," Nature, vol. 407, no. 6805, pp. 770-776, 2000.

[5] A. Degterev, M. Boyce, and J. Yuan, "A decade of caspases," Oncogene, vol. 22, no. 53, pp. 8543-8567, 2003.

[6] F. C. Kischkel, S. Hellbardt, I. Behrmann, et al., "Cytotoxicitydependent APO-1 (Fas/CD95)-associated proteins form a death-inducing signaling complex (DISC) with the receptor," The EMBO Journal, vol. 14, no. 22, pp. 5579-5588, 1995.

[7] A. Ashkenazi, "Targeting the extrinsic apoptosis pathway in cancer," Cytokine and Growth Factor Reviews, vol. 19, no. 3-4, pp. 325-331, 2008.

[8] J. M. Adams and S. Cory, "The Bcl-2 apoptotic switch in cancer development and therapy," Oncogene, vol. 26, no. 9, pp. 1324-1337, 2007.

[9] G. Kroemer, L. Galluzzi, and C. Brenner, "Mitochondrial membrane permeabilization in cell death," Physiological Reviews, vol. 87, no. 1, pp. 99-163, 2007.

[10] E. C. LaCasse, D. J. Mahoney, H. H. Cheung, S. Plenchette, S. Baird, and R. G. Korneluk, "IAP-targeted therapies for cancer," Oncogene, vol. 27, no. 48, pp. 6252-6275, 2008.

[11] S. Fulda and K.-M. Debatin, "Apoptosis signaling pathways in anticancer therapy," Current Cancer Therapy Reviews, vol. 4, no. 1, pp. 14-20, 2008.

[12] W. P. Roos and B. Kaina, "DNA damage-induced cell death by apoptosis," Trends in Molecular Medicine, vol. 12, no. 9, pp. 440-450, 2006.

[13] N. D. Perkins and T. D. Gilmore, "Good cop, bad cop: the different faces of NF- $\kappa \mathrm{B}$," Cell Death and Differentiation, vol. 13, no. 5, pp. 759-772, 2006.

[14] C. R. Weston and R. J. Davis, "The JNK signal transduction pathway," Current Opinion in Cell Biology, vol. 19, no. 2, pp. 142-149, 2007.

[15] M. Loesch and G. Chen, "The p38 MAPK stress pathway as a tumor suppressor or more?" Frontiers in Bioscience, vol. 13, no. 9, pp. 3581-3593, 2008.

[16] H. Okada and T. W. Mak, "Pathways of apoptotic and nonapoptotic death in tumour cells," Nature Reviews Cancer, vol. 4, no. 8, pp. 592-603, 2004.

[17] Y. Kondo, T. Kanzawa, R. Sawaya, and S. Kondo, "The role of autophagy in cancer development and response to therapy," Nature Reviews Cancer, vol. 5, no. 9, pp. 726-734, 2005.

[18] S. Fulda, "Tumor resistance to apoptosis," International Journal of Cancer, vol. 124, no. 3, pp. 511-515, 2009.

[19] I. Lavrik, A. Golks, and P. H. Krammer, "Death receptor signaling," Journal of Cell Science, vol. 118, no. 2, pp. 265-267, 2005.

[20] C. Friesen, S. Fulda, and K.-M. Debatin, "Deficient activation of the CD95 (APO-1/Fas) system in drug-resistant cells," Leukemia, vol. 11, no. 11, pp. 1833-1841, 1997.

[21] S. Fulda, M. Los, C. Friesen, and K.-M. Debatin, "Chemosensitivity of solid tumor cells in vitro is related to activation of the CD95 system," International Journal of Cancer, vol. 76, no. 1, pp. 105-114, 1998.

[22] Z. Jin, E. R. McDonald III, D. T. Dicker, and W. S. El-Deiry, "Deficient tumor necrosis factor-related apoptosis-inducing ligand (TRAIL) death receptor transport to the cell surface in human colon cancer cells selected for resistance to TRAILinduced apoptosis," The Journal of Biological Chemistry, vol. 279, no. 34, pp. 35829-35839, 2004.

[23] I. Petak, R. P. Danam, D. M. Tillman, et al., "Hypermethylation of the gene promoter and enhancer region can regulate
Fas expression and sensitivity in colon carcinoma," Cell Death and Differentiation, vol. 10, no. 2, pp. 211-217, 2003.

[24] M. M. Van Noesel, S. Van Bezouw, G. S. Salomons, et al., "Tumor-specific down-regulation of the tumor necrosis factor-related apoptosis-inducing ligand decoy receptors DcR1 and DcR2 is associated with dense promoter hypermethylation," Cancer Research, vol. 62, no. 7, pp. 2157-2161, 2002.

[25] R. M. Pitti, S. A. Marsters, D. A. Lawrence, et al., "Genomic amplification of a decoy receptor for Fas ligand in lung and colon cancer," Nature, vol. 396, no. 6712, pp. 699-703, 1998.

[26] W. Roth, S. Isenmann, M. Nakamura, et al., "Soluble decoy receptor 3 is expressed by malignant gliomas and suppresses CD95 ligand-induced apoptosis and chemotaxis," Cancer Research, vol. 61, no. 6, pp. 2759-2765, 2001.

[27] M. S. Sheikh, Y. Huang, E. A. Fernandez-Salas, et al., "The antiapoptotic decoy receptor TRID/TRAIL-R3 is a p53regulated DNA damage-inducible gene that is overexpressed in primary tumors of the gastrointestinal tract," Oncogene, vol. 18, no. 28, pp. 4153-4159, 1999.

[28] O. Micheau, "Cellular FLICE-inhibitory protein: an attractive therapeutic target?" Expert Opinion on Therapeutic Targets, vol. 7, no. 4, pp. 559-573, 2003.

[29] B. C. Barnhart, J. C. Lee, E. C. Alappat, and M. E. Peter, "The death effector domain protein family," Oncogene, vol. 22, no. 53, pp. 8634-8644, 2003.

[30] X. Wang, Y. Wang, H. P. Kim, A. M. K. Choi, and S. W. Ryter, "FLIP inhibits endothelial cell apoptosis during hyperoxia by suppressing Bax," Free Radical Biology and Medicine, vol. 42, no. 10, pp. 1599-1609, 2007.

[31] H. S. Kim, J. W. Lee, Y. H. Soung, et al., "Inactivating mutations of caspase- 8 gene in colorectal carcinomas," Gastroenterology, vol. 125, no. 3, pp. 708-715, 2003.

[32] S. Mandruzzato, F. Brasseur, G. Andry, T. Boon, and P. Van der Bruggen, "A CASP-8 mutation recognized by cytolytic T lymphocytes on a human head and neck carcinoma," Journal of Experimental Medicine, vol. 186, no. 5, pp. 785-793, 1997.

[33] T. Teitz, W. Wei, M. B. Valentine, et al., "Caspase 8 is deleted or silenced preferentially in childhood neuroblastomas with amplification of MYCN," Nature Medicine, vol. 6, no. 5, pp. 529-535, 2000.

[34] M. A. Miller, B. Karacay, X. Zhu, M. S. O'Dorisio, and A. D. Sandler, "Caspase 8L, a novel inhibitory isoform of caspase 8, is associated with undifferentiated neuroblastoma," Apoptosis, vol. 11, no. 1, pp. 15-24, 2006.

[35] A. Mohr, R. M. Zwacka, G. Jarmy, et al., "Caspase-8L expression protects $\mathrm{CD} 34+$ hematopoietic progenitor cells and leukemic cells from CD95-mediated apoptosis," Oncogene, vol. 24, no. 14, pp. 2421-2429, 2005.

[36] S. Fulda, M. U. Küfer, E. Meyer, F. van Valen, B. DockhornDworniczak, and K.-M. Debatin, "Sensitization for death receptor- or drug-induced apoptosis by re-expression of caspase- 8 through demethylation or gene transfer," Oncogene, vol. 20, no. 41, pp. 5865-5877, 2001.

[37] S. Hopkins-Donaldson, A. Ziegler, S. Kurtz, et al., "Silencing of death receptor and caspase- 8 expression in small cell lung carcinoma cell lines tumors by DNA methylation," Cell Death and Differentiation, vol. 10, no. 3, pp. 356-364, 2003.

[38] C. Pingoud-Meier, D. Lang, A. J. Janss, et al., "Loss of caspase8 protein expression correlates with unfavorable survival outcome in childhood medulloblastoma," Clinical Cancer Research, vol. 9, no. 17, pp. 6401-6409, 2003. 
[39] K. Harada, S. Toyooka, N. Shivapurkar, et al., "Deregulation of caspase 8 and 10 expression in pediatric tumors and cell lines," Cancer Research, vol. 62, no. 20, pp. 5897-5901, 2002.

[40] S. Cursi, A. Rufini, V. Stagni, et al., "Src kinase phosphorylates caspase- 8 on Tyr380: a novel mechanism of apoptosis suppression," The EMBO Journal, vol. 25, no. 9, pp. 1895-1905, 2006.

[41] A. Letai, M. C. Bassik, L. D. Walensky, M. D. Sorcinelli, S. Weiler, and S. J. Korsmeyer, "Distinct BH3 domains either sensitize or activate mitochondrial apoptosis, serving as prototype cancer therapeutics," Cancer Cell, vol. 2, no. 3, pp. 183-192, 2002.

[42] L. Chen, S. N. Willis, A. Wei, et al., "Differential targeting of prosurvival $\mathrm{Bcl}-2$ proteins by their $\mathrm{BH} 3$-only ligands allows complementary apoptotic function," Molecular Cell, vol. 17, no. 3, pp. 393-403, 2005.

[43] S. N. Willis, J. I. Fletcher, T. Kaufmann, et al., "Apoptosis initiated when $\mathrm{BH} 3$ ligands engage multiple Bcl-2 homologs, not Bax or Bak," Science, vol. 315, no. 5813, pp. 856-859, 2007.

[44] Z. X. Chen and S. Pervaiz, "BCL-2: pro-or anti-oxidant?" Frontiers in Bioscience, vol. 1, pp. 263-268, 2009.

[45] W. Dröge, "Free radicals in the physiological control of cell function," Physiological Reviews, vol. 82, no. 1, pp. 47-95, 2002.

[46] D. M. Hockenbery, Z. N. Oltvai, X.-M. Yin, C. L. Milliman, and S. J. Korsmeyer, "Bcl-2 functions in an antioxidant pathway to prevent apoptosis," Cell, vol. 75, no. 2, pp. 241251, 1993.

[47] M.-V. Clément, J. L. Hirpara, and S. Pervaiz, "Decrease in intracellular superoxide sensitizes Bcl-2-overexpressing tumor cells to receptor and drug-induced apoptosis independent of the mitochondria," Cell Death and Differentiation, vol. 10, no. 11, pp. 1273-1285, 2003.

[48] Z. T. Schafer and S. Kornbluth, "The apoptosome: physiological, developmental, and pathological modes of regulation," Developmental Cell, vol. 10, no. 5, pp. 549-561, 2006.

[49] V. Borutaite and G. C. Brown, "Mitochondrial regulation of caspase activation by cytochrome oxidase and tetramethylphenylenediamine via cytosolic cytochrome c redox state," The Journal of Biological Chemistry, vol. 282, no. 43, pp. 31124-31130, 2007.

[50] Z. Pan, D. W. Voehringer, and R. E. Meyn, "Analysis of redox regulation of cytochrome c-induced apoptosis in a cell-free system," Cell Death and Differentiation, vol. 6, no. 7, pp. 683688, 1999.

[51] D. Suto, K. Sato, Y. Ohba, T. Yoshimura, and J. Fujii, "Suppression of the pro-apoptotic function of cytochrome c by singlet oxygen via a haem redox state-independent mechanism," Biochemical Journal, vol. 392, no. 2, part 2, pp. 399-406, 2005.

[52] I. Sturm, A. G. Bosanquet, S. Radetzki, M. Hummel, B. Dörken, and P. T. Daniel, "Silencing of APAF-1 in B-CLL results in poor prognosis in the case of concomitant p53 mutation," International Journal of Cancer, vol. 118, no. 9, pp. 2329-2336, 2006.

[53] M. S. Soengas, P. Capodieci, D. Polsky, et al., "Inactivation of the apoptosis effector Apaf-1 in malignant melanoma," Nature, vol. 409, no. 6817, pp. 207-211, 2001.

[54] W.-N. Fu, F. Bertoni, S. M. Kelsey, et al., "Role of DNA methylation in the suppression of Apaf-1 protein in human leukaemia," Oncogene, vol. 22, no. 3, pp. 451-455, 2003.

[55] H.-L. Wang, H. Bai, Y. Li, J. Sun, and X.-Q. Wang, "Rationales for expression and altered expression of apoptotic protease activating factor-1 gene in gastric cancer," World Journal of Gastroenterology, vol. 13, no. 38, pp. 5060-5064, 2007.
[56] T. Watanabe, Y. Hirota, Y. Arakawa, et al., "Frequent LOH at chromosome 12q22-23 and Apaf-1 inactivation in glioblastoma," Brain Pathology, vol. 13, no. 4, pp. 431-439, 2003.

[57] S. Fulda, "Targeting inhibitor of apoptosis proteins (IAPs) for cancer therapy," Anti-Cancer Agents in Medicinal Chemistry, vol. 8, no. 5, pp. 533-539, 2008.

[58] E. N. Shiozaki and Y. Shi, "Caspases, IAPs and Smac/DIABLO: mechanisms from structural biology," Trends in Biochemical Sciences, vol. 29, no. 9, pp. 486-494, 2004.

[59] B. P. Eckelman, G. S. Salvesen, and F. L. Scott, "Human inhibitor of apoptosis proteins: why XIAP is the black sheep of the family," The EMBO Reports, vol. 7, no. 10, pp. 988-994, 2006.

[60] S. M. Lewis and M. Holcik, "IRES in distress: translational regulation of the inhibitor of apoptosis proteins XIAP and HIAP2 during cell stress," Cell Death and Differentiation, vol. 12, no. 6, pp. 547-553, 2005.

[61] X. Saelens, M. Kalai, and P. Vandenabeele, "Translation inhibition in apoptosis: caspase-dependent PKR activation and eIF2- $\alpha$ phosphorylation," The Journal of Biological Chemistry, vol. 276, no. 45, pp. 41620-41628, 2001.

[62] L. D. Kapp and J. R. Lorsch, "The molecular mechanics of eukaryotic translation," Annual Review of Biochemistry, vol. 73, pp. 657-704, 2004.

[63] M. Holcik, C. Yeh, R. G. Korneluk, and T. Chow, "Translational upregulation of X-linked inhibitor of apoptosis (XIAP) increases resistance to radiation induced cell death," Oncogene, vol. 19, no. 36, pp. 4174-4177, 2000.

[64] M. Holcik, C. Lefebvre, C. Yeh, T. Chow, and R. G. Korneluk, "A new internal-ribosome-entry-site motif potentiates XIAPmediated cytoprotection," Nature Cell Biology, vol. 1, no. 3, pp. 190-192, 1999.

[65] D. Warnakulasuriyarachchi, S. Cerquozzi, H. H. Cheung, and M. Holcík, "Translational induction of the inhibitor of apoptosis protein HIAP2 during endoplasmic reticulum stress attenuates cell death and is mediated via an inducible internal ribosome entry site element," The Journal of Biological Chemistry, vol. 279, no. 17, pp. 17148-17157, 2004.

[66] M. E. Van Eden, M. P. Byrd, K. W. Sherrill, and R. E. Lloyd, "Translation of cellular inhibitor of apoptosis protein 1 (cIAP1) mRNA is IRES mediated and regulated during cell stress," RNA, vol. 10, no. 3, pp. 469-481, 2004. 

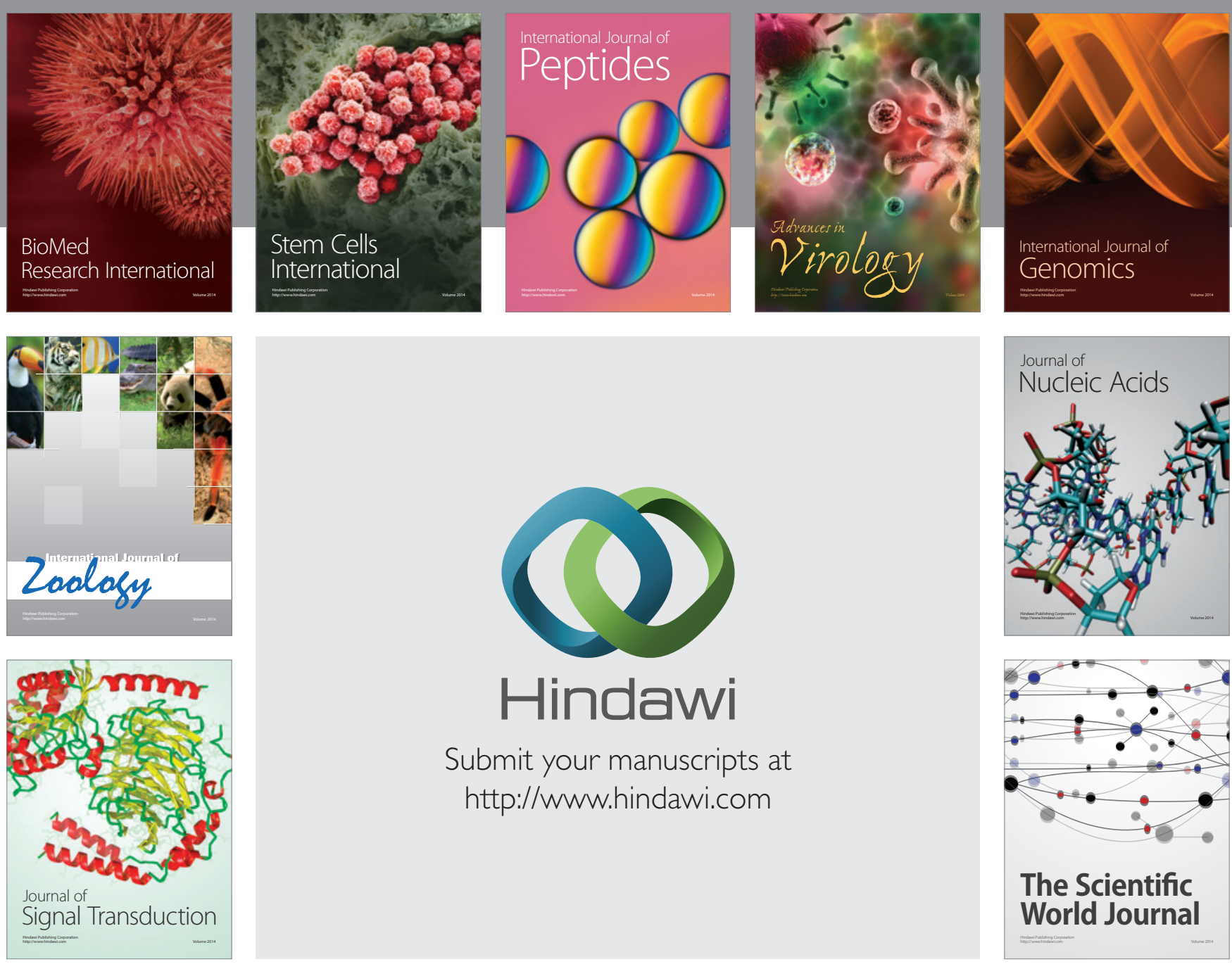

Submit your manuscripts at

http://www.hindawi.com
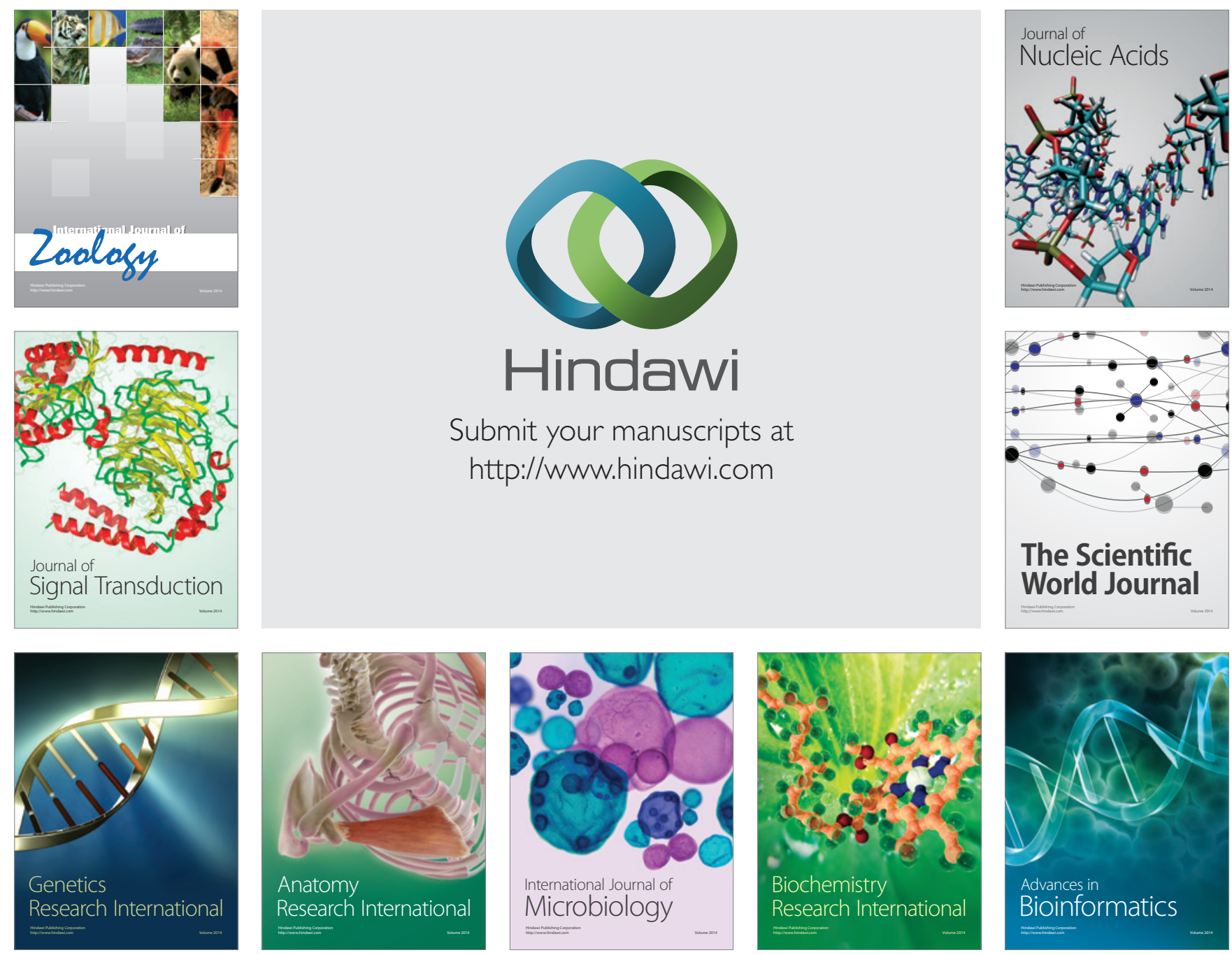

The Scientific World Journal
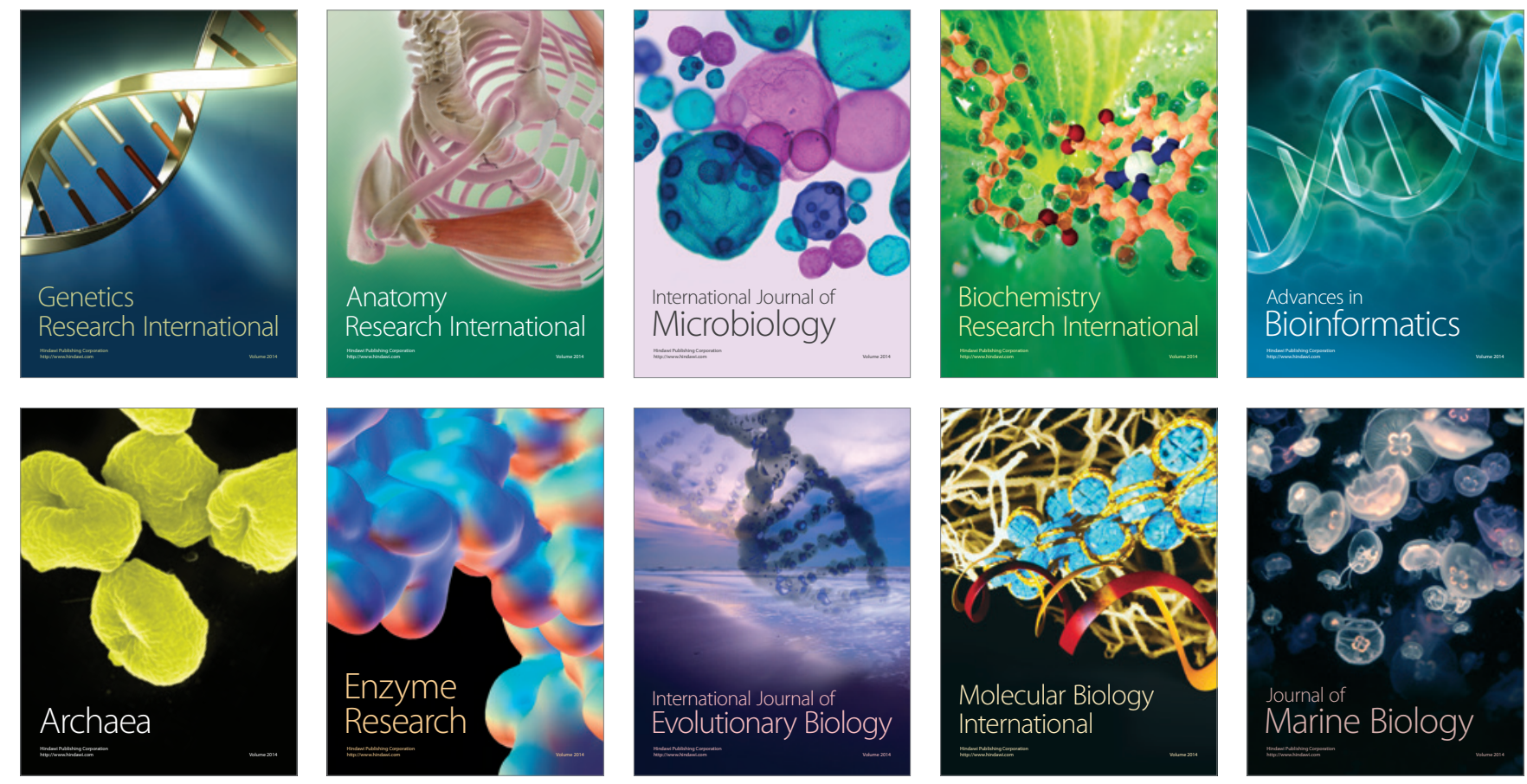